\title{
Sub-bandgap optical absorption spectroscopy of hydrogenated microcrystalline silicon thin films prepared using hot-wire CVD (Cat-CVD) process
}

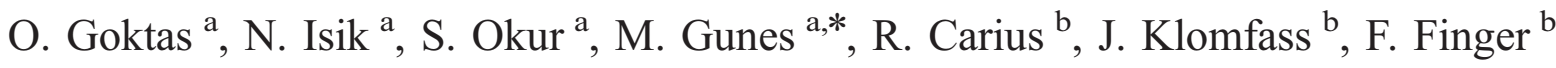 \\ a Department of Physics, Izmir Institute of Technology, Gülbahce Kampusü, Urla, Izmir, Turkey \\ ${ }^{\mathrm{b}}$ Institut für Photovoltaik, Forschungszentrum Jülich GmbH, 52425 Jülich, Germany
}

Available online 11 August 2005

\begin{abstract}
Hydrogenated microcrystalline silicon ( $\mu \mathrm{c}-\mathrm{Si}: \mathrm{H})$ thin films with different silane concentration (SC) have been prepared using the HWCVD technique. Dual beam photoconductivity (DBP), photothermal deflection spectroscopy (PDS), and transmission measurements have been used to investigate the optical properties of the $\mu \mathrm{c}-\mathrm{Si}: \mathrm{H}$ films. Two different sub-bandgap absorption, $\alpha(h v)$, methods have been applied and analyzed to obtain a better insight into the electronic states involved. A good agreement has been obtained in the absorption spectrum obtained from the PDS and DBP measurements at energies above the bandgap. Differences between PDS and DBP spectra exist below the bandgap energy where DBP spectra always give lower $\alpha(h v)$ values and show a dependence on the SC. For some films, differences exist in the $\alpha(h v)$ spectra when the DBP measurements are carried out through the film and substrate side. In addition, for some films, there remains fringe pattern left on the spectrum after the calculation of the fringe-free absorption spectrum, which indicates structural inhomogeneities present throughout the film.
\end{abstract}

(C) 2005 Elsevier B.V. All rights reserved.

Keywords: Microcrystalline silicon thin films; Optical properties; Electrical properties and measurements; Hot-wire deposition

\section{Introduction}

Hydrogenated microcrystalline silicon ( $\mu \mathrm{c}-\mathrm{Si}: \mathrm{H})$ thin films have become an important candidate for large area photovoltaic applications $[1,2]$. Hot-wire chemical (catalytic) vapor deposition (HW-CVD) method has become an important deposition method to prepare device quality intrinsic $\mu \mathrm{c}-\mathrm{Si}: \mathrm{H}$ thin films and solar cells [3,4] due to its higher deposition rates and its potential for an easy industrial scaling-up. An intrinsic characteristic of the $\mu \mathrm{c}-$ $\mathrm{Si}: \mathrm{H}$ is its microstructure which is mainly controlled by varying the silane concentration, $\mathrm{SC}$ (gas flow ratio [SiH4]/ $[\mathrm{SiH} 4+\mathrm{H} 2]$ ), during deposition. As a result, the changes in its microstructure substantially affect its both electronic and optical properties of the material. An important property of

\footnotetext{
* Corresponding author.

E-mail address: M.gunes@tnn.net (M. Gunes).
}

intrinsic $\mu \mathrm{c}-\mathrm{Si}: \mathrm{H}$ thin films is the optical absorption coefficient, $\alpha(h v)$, spectrum especially at the sub-bandgap energies which generally correlate with the defect states present in the material. Well established methods such as photothermal deflection spectroscopy (PDS) [5] and transmission and reflection spectroscopy (T and R) [6] have been extensively used to measure the absolute $\alpha(h v)$ spectrum. However, both methods have limitations at lower energies to obtain reliable $\alpha(h v)$ values. Alternatively, photoconductivity techniques such as constant photocurrent method (CPM), both in standard [7] and absolute mode [8] and dual beam photoconductivity (DBP) [9] techniques have been used to derive absorption coefficients from the measured photoconductivity spectrum. No study has been reported for the direct calculation of absolute $\alpha(h v)$ spectrum using the DBP method yet. In the present work, DBP yield spectrum and simultaneously measured transmission signal have been used to calculate the fringe-free $\alpha(h v)$ spectrum of intrinsic $\mu \mathrm{c}-\mathrm{Si}: \mathrm{H}$ films deposited with different SC using the HW- 
CVD method and compared with that independently obtained from PDS measurements to gain a better insight into the electronic states involved.

\section{Experimental details}

Intrinsic $\mu \mathrm{c}-\mathrm{Si}: \mathrm{H}$ thin films were prepared using the HWCVD chamber of a multichamber deposition system with three PECVD chambers and one HW-CVD chamber at Research Center Juelich on a borosilicate glass substrate with varying silane concentrations from $2 \%$ to $7 \%$ at substrate temperatures between $185{ }^{\circ} \mathrm{C}$ and $220{ }^{\circ} \mathrm{C}[3,4]$. The film thickness is between $0.4 \mu \mathrm{m}$ and $0.80 \mu \mathrm{m}$ and metal contacts have $0.5 \mathrm{~mm}$ width and $0.5 \mathrm{~cm}$ length. The applied dc bias was in the Ohmic region of the contacts. A standard PDS system [5] was used to measure raw PDS spectrum and the corresponding transmission signal was simultaneously measured from the back of the sample. Detailed description of the DBP method applied for the $\mu \mathrm{c}-$ $\mathrm{Si}: \mathrm{H}$ films can be found elsewhere [9]. Here, DBP measurements were carried out for different dc bias light intensities for both ac light illumination through the film and the substrate side. Corresponding transmission spectra were measured from the substrate and the film side, respectively. Interference fringe-free absolute $\alpha(h v)$ spectra were calculated for both PDS and DBP spectra using a procedure [10] based on the Ritter-Weiser formula [11]. Crystalline volume fraction, $I_{\mathrm{c}}^{\mathrm{RS}}$, values are obtained from the Raman measurements carried out on the same samples.

\section{Results and discussions}

In Fig. 1, raw PDS and relative DBP Yield spectra, $Y_{\mathrm{DBP}}(h v)=\sigma_{\mathrm{ph}}(\mathrm{ac})(h v) /$ Flux $(h v)$, measured at two different bias light intensities are shown for a $\mu \mathrm{c}-\mathrm{Si}: \mathrm{H}$ thin film prepared with $\mathrm{SC}=4 \%$. In the spectra of both methods, there exist interference fringes for thin samples. In the DBP spectra, there exists a difference at sub-bandgap energies. Low bias DBP spectrum was measured at very low generation rates $\left(1-2 \times 10^{16} \mathrm{~cm}^{-3} \mathrm{~s}^{-1}\right)$ and results in the lowest values. As the intensity of bias light is increased, an increase in the DBP signal is observed at lower energies below the bandgap due to an increase in transitions from the occupied defect states into the bandgap.

The fringe-free $\alpha(h v)$ spectrum is calculated from the raw PDS spectrum and simultaneously measured transmission signal using a procedure [10] based on the Ritter-Weiser formula [11]. This is shown in Fig. 2 as open squares. The $\alpha(h v)$ at low energies are high due to significant substrate absorption. A correction for the PDS spectrum was carried out using the changes in the phase of PDS signal shown in the inset of Fig. 1. However, the accuracy of the phase correction procedure is not better than a factor of two as represented by solid squares in Fig. 2 due to noise in the

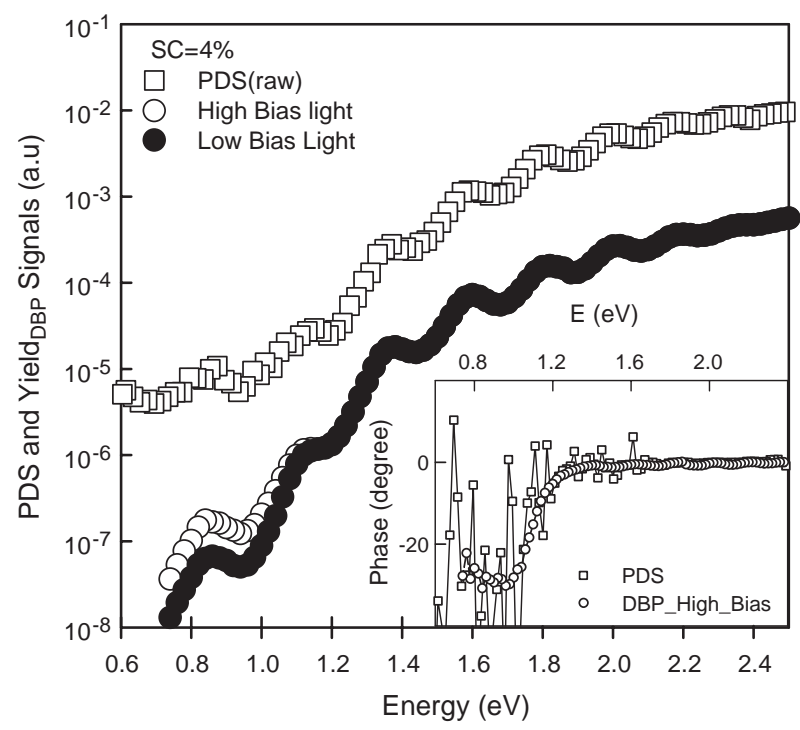

Fig. 1. DBP yield spectra measured at high and low bias light intensities, and raw PDS spectrum for an intrinsic $\mu \mathrm{c}-\mathrm{Si}: \mathrm{H}$ thin film prepared using the HW-CVD method with $\mathrm{SC}=4 \%$. In the inset, the phase signals of both PDS and DBP are shown.

phase signal. DBP yield is a relative measurement and it requires a normalization to an absolute scale to obtain defect related $\alpha(h v)$ values at lower energies, as commonly practiced in the literature [12]. In this study, for the first time, the absolute $\alpha(h v)$ spectrum is calculated from the relative $Y_{\mathrm{DBP}}$ spectrum and simultaneously measured transmission signal using the same calculation procedure of PDS spectrum, without carrying out any normalization to the absolute $\alpha(h v)$ spectrum of PDS. The $\alpha(h v)$ spectra of DBP for low and high bias light intensities are also shown in Fig. 2 together with those of PDS. It is seen that there is a good agreement between PDS and DBP spectra at higher energies indicating that both methods probe the same distribution of defect states. At lower energies, low bias light DBP spectrum yields the lower $\alpha(h v)$ values. The $\alpha(h v)$ values derived from the DBP measurements below the bandgap energy do not reflect the absolute absorption coefficient spectrum, but rather the effects of the electron occupied defect states are probed. Therefore, the $\alpha(h v)$ spectrum at lower energies can easily be changed by increasing the intensity of the bias light as seen in Fig. 2 with open circle symbols for high bias light DBP spectrum.

The $\alpha(h v)$ spectra of Fig. 2 indicate that there is a very small fringe pattern left on the spectra after fringe-free calculation of the $\alpha(h v)$ spectrum for both PDS and DBP measurements, which indicates structural inhomogeneities of the material in growth direction. This is also reflected in the phase of both signals as shown in the inset of Fig. 1. In microcrystalline silicon growth, initially more defective amorphous incubation layer forms, then columnar crystalline regions grow directionally [13]. To investigate the effect of the amorphous layer and differences in directional growth processes, we have performed the DBP measurement on the 


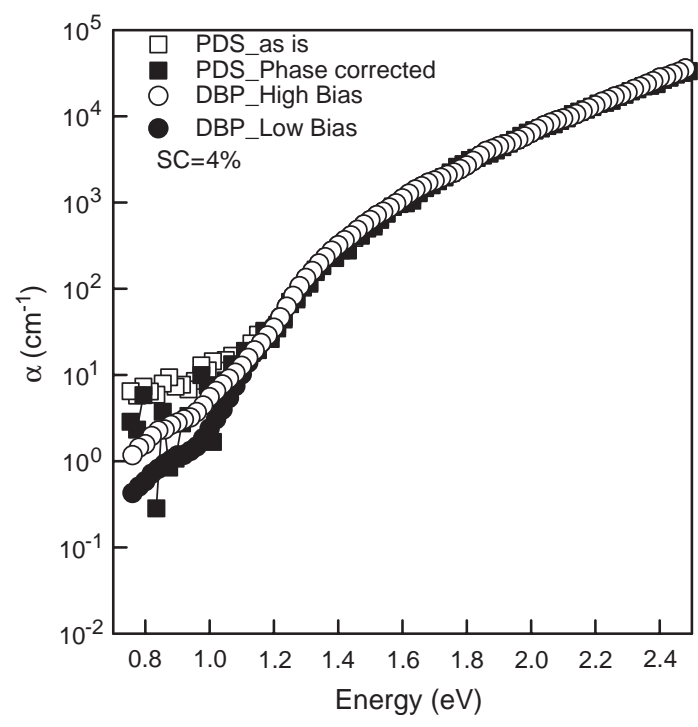

Fig. 2. The absolute absorption coefficient spectra calculated from the raw PDS and DBP measurements shown in Fig. 1 for an intrinsic $\mu \mathrm{c}-\mathrm{Si}: \mathrm{H}$ thin film prepared using $\mathrm{HW}-\mathrm{CVD}$ method with $\mathrm{SC}=4 \%$ (for details, see text).

same sample by illuminating the ac monochromatic light through the substrate side by maintaining the same intensity and direction of dc bias light. The resulting calculated $\alpha(h v)$ spectra for the front and back ac illumination are shown in Fig. 3 together with that of PDS.

It is clearly seen that there remain interference fringes with a large modulation depth after fringe-free calculation of the $\alpha(h v)$ spectrum. It can be inferred that there exists a defective interfacial layer, which causes a large recombination and a decrease in photoresponse, which is not reflected in the transmission signals of three measurements as they are almost identical as shown in the inset of Fig. 3. Similar

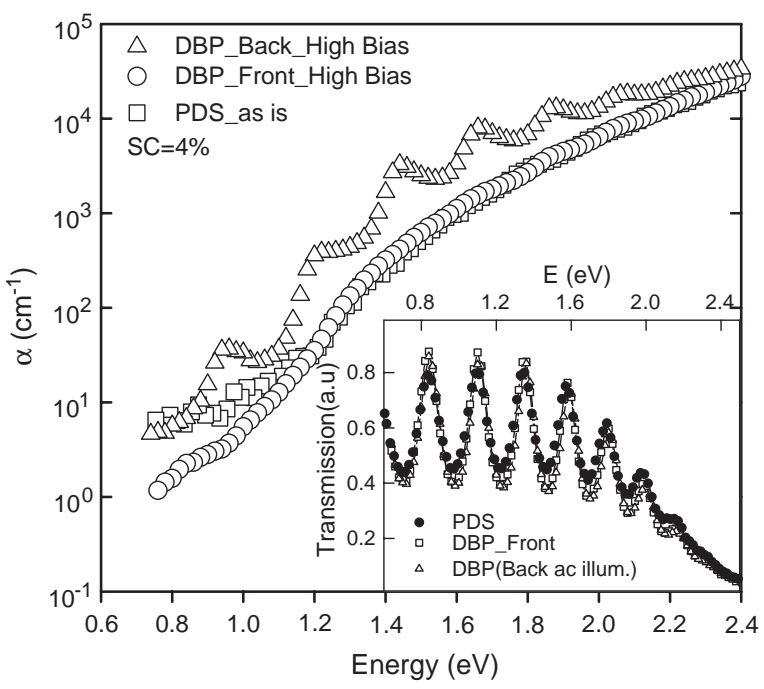

Fig. 3. The absolute absorption coefficient spectra calculated from the raw PDS and DBP front and back illumination measurements for an intrinsic $\mu \mathrm{c}-\mathrm{Si}$ :H thin film prepared using HW-CVD method with $\mathrm{SC}=4 \%$. The inset displays corresponding transmission signals for PDS, DBP front, and DBP back ac illumination measurement. effect has been observed in other $\mu \mathrm{c}-\mathrm{Si}: \mathrm{H}$ films deposited with different SCs but the degree of this deviation from the front ac illuminated DBP spectrum shows a variation among the samples. However, generally the $\alpha(h v)$ spectra of PDS and front ac illumination DBP measurement show a good agreement at energies above the bandgap energy for other samples used in this study. For low bias light condition, DBP probes the transitions from the distribution of occupied defect states into the bandgap, which is slightly modified from that in the dark. In order to investigate the effects of the changing microstructure on the $\alpha(h v)$ values at subbandgap energies, phase corrected PDS and low bias light DBP front ac illumination spectra are used to compare different $\mu \mathrm{c}-\mathrm{Si}: \mathrm{H}$ films. To represent the changes in microstructure, the crystalline volume fraction $I_{\mathrm{c}}^{\mathrm{RS}}$ values are used instead of the silane concentration (SC). This allows us to compare different samples prepared with slightly different deposition conditions.

In Fig. 4, the $\alpha(h v)$ values at $0.8 \mathrm{eV}$ versus $I_{\mathrm{c}}^{\mathrm{RS}}$ are shown for intrinsic $\mu \mathrm{c}-\mathrm{Si}: \mathrm{H}$ films deposited using the HW-CVD method. The $\alpha(0.8 \mathrm{eV})$ values measured by low bias light DBP are lower than those obtained from the phase corrected PDS measurement. The PDS and DBP curves differ by approximately a factor of two. Both curves show a decrease as $I_{\mathrm{c}}^{\mathrm{RS}}$ decreases and give the lowest $\alpha(0.8 \mathrm{eV})$ value around $I_{\mathrm{c}}^{\mathrm{RS}}=0.5$, which corresponds to the transition to amorphous growth. Then $\alpha(0.8 \mathrm{eV})$ tends to increase for lower $I_{\mathrm{c}}^{\mathrm{RS}}$ values. The results in Fig. 4 indicate that intrinsic $\mu \mathrm{c}-\mathrm{Si}: \mathrm{H}$ thin films deposited in the transition region have the lowest defect density and will result in a better performance when solar cells are fabricated using these materials as absorber layers. These results are consistent with the defect density measured using the ESR method for the same series of samples [14] and with the recent observations reported for the highest efficiency solar cells prepared by the HW-CVD method $[3,4,15,16]$.

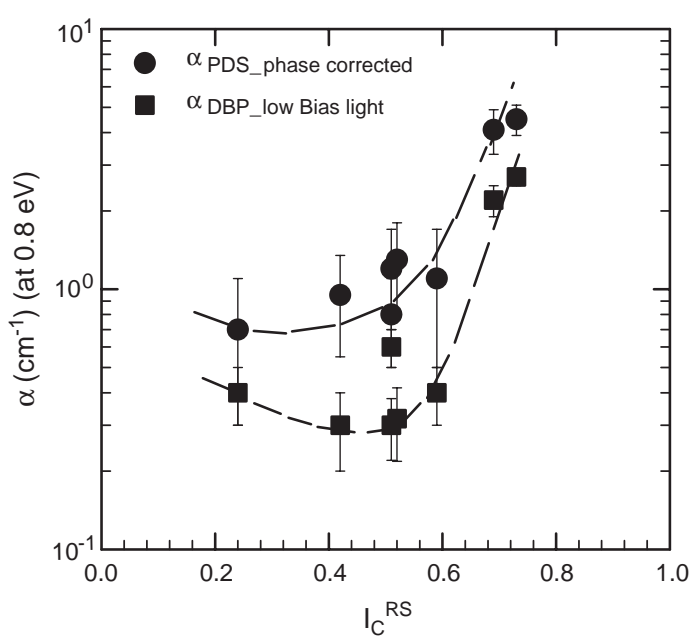

Fig. 4. The sub-bandgap absorption coefficient at $0.8 \mathrm{eV}$ obtained from the phase corrected PDS and low bias light DBP spectra versus the crystalline volume fraction, $I_{\mathrm{c}}^{\mathrm{RS}}$ for intrinsic $\mu \mathrm{c}-\mathrm{Si}$ :H thin films prepared using HWCVD method. 


\section{Conclusions}

Reliable and consistent $\alpha(h v)$ spectra of $\mu \mathrm{c}-\mathrm{Si}: \mathrm{H}$ films are obtained from both PDS and DBP yield spectra together with simultaneously measured optical transmission. A good overlap in the spectra above $1.1 \mathrm{eV}$ is obtained for most of the samples. For some samples, there remains a fringe pattern on the $\alpha(h v)$ spectrum after the fringe-free calculation procedure due to structural inhomogeneities present in the films. For some cases, an interfacial layer can form during deposition at the film-substrate interface, which can strongly affect the DBP back ac illumination measurement. A systematic difference observed between two methods is consistent since the PDS method detects all transitions from occupied states into empty states when light photons are absorbed. However, low bias light DBP measurement can only detect the free electrons in the conduction band due to transitions from the occupied defect states into the empty conduction band extended states, not those transitions into states just above the Fermi level. The effect of microstructure characterized by $\alpha(0.8 \mathrm{eV})$ as a function of $I_{\mathrm{c}}^{\mathrm{RS}}$ indicates that intrinsic films with the lowest defect density are prepared at the transition region to amorphous growth.

\section{Acknowledgements}

The authors thank S. Klein, A. Gross, M. Hülsbeck, A. Lambertz, and J. Wolff for helping with the sample preparation and measurements. This joint project is partially supported by the International Bureau of the BMBF, Germany, under project number 42.4.I3B.2.A and The
Scientific and Technical Research Council of Turkey (TÜBÝTAK) under the project number TBAG-U/14.

\section{References}

[1] A. Shah, E. Vallat-Sauvain, P. Torres, J. Meier, U. Kroll, C. Hof, C. Droz, M. Goerlitzer, N. Wyrsch, M. Vanacek, Mater. Sci. Eng., B 69/70 (2000) 219.

[2] O. Vetterl, F. Finger, R. Carius, P. Hapke, L. Houben, O. Kluth, A. Lambertz, A. Mück, B. Rech, H. Wagner, Sol. Energy Mater. Sol. Cells 62 (2000) 97.

[3] S. Klein, F. Finger, R. Carius, H. Wagner, M. Stutzmann, Thin Solid Films 395 (2001) 305.

[4] S. Klein, F. Finger, R. Carius, T. Dylla, B. Rech, M. Grimm, L. Houben, M. Stutzmann, Thin Solid Films 430 (2003) 202.

[5] W.B. Jackson, N.M. Amer, Phys. Rev., B 25 (1982) 5559.

[6] G.D. Cody, C.R. Wronski, B. Abeles, R.B. Stephens, B. Brooks, Solar Cells 2 (1980) 227.

[7] M. Vanacek, J. Kocka, J. Stuchlik, A. Triska, Solid State Commun. 39 (1981) 1199

[8] M. Vanacek, J. Kocka, A. Poruba, A. Fejfar, J. Appl. Phys. 78 (1995) 6203.

[9] M. Güneş, D. Akdaş, O. Göktaş, R. Carius, J. Klomfass, F. Finger, J. Mater. Sci., Mater. Electron. 14 (2003) 729.

[10] R. Carius, Research Center Jülich, Germany. Private Communication.

[11] D. Ritter, K. Weiser, Opt. Commun. 57 (1986) 336.

[12] I. Chen, L. Jiao, R.W. Collins, C.R. Wronski, J. Non-Cryst. Solids 198-200 (391) (1996).

[13] L. Houben, M. Luysberg, P. Hapke, R. Carius, F. Finger, H. Wagner, Philos. Mag., A 77 (1998) 1447.

[14] F. Finger, A.L. Baia Neto, R. Carius, T. Dylla, S. Klein, Phys. Stat. Solidi C 1 (2004) 1248.

[15] S. Klein, J. Wolf, F. Finger, R. Carius, H. Wagner, M. Stutzmann, Jpn. J. Appl. Phys. 41 (L10) (2002).

[16] S. Klein, F. Finger, R. Carius, B. Rech, L. Houben, M. Luysberg, M. Stutzmann, Mater. Res. Soc. Symp. Proc. 715 (2002) A23.3. 